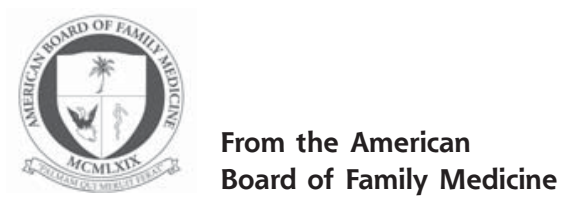

Ann Fam Med 2011;9:180. doi:10.1370/afm.1235.

\section{ABFM Introduces Important Enhancements to MC-FP}

The American Board of Family Medicine (ABFM) has always maintained that it would listen carefully to feedback and concerns from Diplomates and would continuously make improvements to Maintenance of Certification for Family Physicians (MC-FP) to simplify and streamline the process, target it to practice needs, and create flexibility in how MC-FP requirements are met.

As of 2011, the ABFM introduced several important enhancements to MC-FP. These changes will affect only those Diplomates certifying or recertifying in 2011 and beyond. The first of these enhancements is that, beginning with those Diplomates that certify or recertify in the summer of 2011, the examination will be temporally unlinked from the MC-FP cycle. While at the present time, MC-FP culminates with the administration of the examination at the end of the cycle, with this change it may be taken at any point in time during the MC-FP cycle, and the results will be valid for up to 10 years.

Secondly, Diplomates certifying in 2011 and after will be allowed to choose how they wish to complete their Part II (SAMs) and Part IV (PPMs, MIMMs, approved alternatives) requirements during each 3-year stage. Each module will be assigned a point value, and each Diplomate will need to accumulate $50 \mathrm{MC}$-FP points every 3 years. How this is accomplished is up to the Diplomate as long as the combination of completed activity includes at least 1 ABFM Self-Assessment Module (SAM) and 1 Part IV quality improvement activity. The basic requirements will be the same for each 3-year period.

Additionally, Diplomates must continuously meet the requirements of all 4 parts of MC-FP to remain certified. With this new format in place, each Diplomate will simply need to meet four requirements during each 3-year stage of the MC-FP cycle to maintain certification:

1. Maintain medical license and keep current record with ABFM (Part I).

2. Complete Part II and Part IV activities totaling 50 MC-FP points with a minimum 1 ABFM SelfAssessment Module (SAM) and 1 Part IV quality improvement activity (Diplomates will continue to receive CME for this activity).
3. Meet ABFM CME requirements of $150 \mathrm{CME}$ credits per stage (Part II).

4. Perform successfully on the examination every 10 years (Part III).

Lastly, the ABFM is awaiting approval from the American Board of Medical Specialties (ABMS) to begin issuing certificates without end dates beginning in the summer. The validity of the new certificates without end dates will be continuous as long as the requirements for the MC-FP program are adhered to and the Diplomate successfully completes the examination every 10 years.

Again, these enhancements will only affect those Diplomates certifying or recertifying in 2011 and beyond. For questions regarding these changes or MC-FP, Diplomates may contact the ABFM Support Center at 877-2237437 or via e-mail at help@theabfm.org.

James C. Puffer, MD

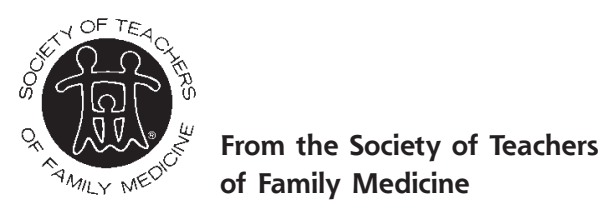

Ann Fam Med 2011;9:180-181. doi:10.1370/afm.1241.

\section{Family Medicine Advocacy-It Depends on All of Us!}

Advocating for our members and promoting the value of family medicine to legislators and policymakers is an important priority for STFM. To do this, STFM gets involved in legislative and regulatory issues that affect our members and family medicine. We also strive to keep our members informed about Washington's legislative and regulatory activities through e-mail alerts and The Briefing Room, a blog-style Web update that you'll find on http://www.stfm.org. Members can learn even more about advocacy at the annual Family Medicine Congressional Conference held in May in Washington DC.

On the STFM Web site, http://www.stfm.org/ advocacy, you'll find links that will give you details of STFM position on the various topics. The links will also provide you with the background and updates on the issues. You'll even find position papers and letters to help you be an effective advocate for academic family medicine.

STFM conducts its legislative activities through the Council of Academic Family Medicine (CAFM). STFM works with CAFM because it allows us to collaborate with other academic family medicine groups, making 
our resources go farther and our efforts more successful. Other groups that are part of CAFM include the Association of Departments of Family Medicine, the Association of Family Medicine Residency Directors, and the North American Primary Care Research Group. We also work in tandem with the American Academy of Family Physicians (AAFP) in our policy development through our Academic Family Medicine Advocacy Committee (AFMAC) — a body that includes the 4 CAFM organizations and the AAFP and meets twice a year. AFMAC is chaired by STFM.

\section{Some Priority Areas Include:}

- Primary care research. AHRQ, the Agency for Healthcare Research and Quality is a small federal agency with the responsibility for research to support clinical decision-making, reduce costs, advance patient safety, and improve health care quality and access. As such, it provides funding for many family medicine and other primary care researchers. Our advocacy efforts support AHRQ and we are exploring other funding streams for primary care research.

- Graduate medical education. STFM, through CAFM, is asking Congress to modernize GME with a system in which Medicare and Medicaid (as well additional funding from private insurers) directly pay primary care residency programs. Our proposed system would do a more efficient job of ensuring that training can be adequately funded in an ambulatory setting. Our proposal would still fund inpatient training, but the control over the funding would be in the hands of the educational entity, not the hospital. We encourage you to read our policy paper, entitled Modernizing Graduate Medical Education to Produce a Healtby America.

- Title VII. STFM annually supports funding for Title VII, specifically for the primary care cluster of Title VII. We support increased funding for primary care training under Title VII to help address the primary care needs of our nation. Right now, being proactive for family medicine education means we must stay abreast of health care reform.

The Patient Protection and Affordable Care Act instituted changes that have drastically changed our health care system. Health care reform legislation included many new and innovative mechanisms that were designed to increase the number of insured individuals and deliver high quality care while lowering the cost of coverage.

Several of these ideas include the creation of state based insurance exchanges, the elimination of life time caps and preexisting condition discrimination, a mandate requiring all individuals purchase health insurance, and tax credits for low income individuals to purchase health insurance.

Also included in the health care reform legislation were many provisions specifically affecting primary care and primary care educators. Some of our advocacy priorities of the Affordable Care Act (ACA)include:

- Primary Care Research-AHRQ and more

- Medicare GME

- Title VII

- Implementation of Selected Primary Care ACA Provisions

You'll find summaries of these provisions and links to the specific bill text on the advocacy pages of stfm.org.

\section{How Do You Get Involved in Family Medicine Advocacy?}

New in 2011, STFM has developed a comprehensive course on advocacy and how you can get involved. No matter what your current level of involvement in advocacy is, we have resources for you.

1. Learn about advocacy. Visit http://www.stfm. org/advocacy to immerse yourself on the key priority topics and how to talk to legislators about these important issues.

2. Train to be an advocate. View the Advocacy Curriculum Introductory Video and take the online Advocacy Course at http://www.stfm.org/advocacy. The Advocacy Course will give you training in the key skills needed to develop a relationship and communicate with your legislators.

3. Participate on the hill. After completing the online course, take another step and get involved in the advocacy process. Attend our Family Medicine Congressional Conference or a state legislative conference. At these conferences you'll be able to put your new knowledge to work for family medicine. Then you'll be recognized with a certificate honoring your involvement and achievement as an advocate of family medicine education.

As always, contact us at STFM if you have comments on advocacy, or if we can be of help in any way. Jerry Kruse, MD, Chair of Academic Family Medicine Advocacy Committee Hope Wittenberg, MA, Director, Government Relations 